\title{
Now, where was I? Negotiating time in digitally augmented autobiographical performance
}

\section{Introduction}

A man mounts a small stage, sits on a chair in front of a projector screen, and begins to speak. The story he wants to tell is of his grandfather's trip from the Midlands to Cape Wrath, the northernmost point in mainland Scotland, but his grandfather is no longer alive. The traces from which the man builds his story are his own memories of his grandfather's story, his mother's memories of that story, and his own re-enactment of the journey more than two decades later. This re-enactment has been documented in still images, video and posts to a social networking site (Figure 1). The performer reaches through his memories to create for himself and for his audience a visceral and empathetic link to a series of past moments he cannot fully know or precisely re-experience, creating a personal identity that he claims for the duration of the performance.

\section{INSERT FIGURE 1 ABOUT HERE.}

Five friends gather around the dinner table. From time to time, a small, four-sided wooden centrepiece catches their attention (Figure 2). It displays photographs drawn automatically from their own Facebook albums. As the images float from one screen to the next around the centrepiece, they invite conversation, reminiscence and animated storytelling. The friends make connections with, and personal claims to, various elements of the memories that they recreate and reinterpret together during the course of their meal. The design of the centrepiece limits the degree to which any individual can dominate the storytelling. Instead, their interactions with it foster free-flowing conversation around personal stories, which reflect the numerous past moments and perspectives of the photographs that trigger them.

\section{INSERT FIGURE 2 ABOUT HERE.}

The Journeys Across Media conference held at the University of Reading in April 2012 encouraged participants to ask broad questions about the workings of time across a number of creative domains, including performance and media. Many responses coalesced around the importance of the present moment of performance as a place and time for co-present performer and audience to engage with memory and identity, particularly relating to everyday 
practices. The conference inspired participants to investigate two key questions: what is the role of personal and autobiographical media in the here and now of live performance? And how can we design for performative experiences using these media?

Both the Cape Wrath performance and the dinner party centrepiece address these questions. They are instances of an everyday, lived practice of sharing digital media resources that we term 'digitally augmented autobiographical performance', the live performance of stories from the teller's own life including images, usually digital projections, representing those past experiences. The term 'performance' applies whether the storyteller is a professional performer on a stage or an individual engaged in dinnertime conversation, following Goffman's (1959) concept of the performance of self in everyday life. We are developing practical and theoretical work on digitally augmented autobiographical performance in two particular contexts: performance and human-computer interaction (HCI). Through this work, we demonstrate the close connections between these two contexts and the value of seeing them as parts of a common practice.

The first section of this article identifies theories that are relevant to digitally augmented autobiographical performance. The second section analyses four instances of the practice drawn from these contexts: two performances by Third Angel, a contemporary UK performance company, and two examples of design for co-located media sharing within the field of HCI research. Through this analysis, we demonstrate and begin to unpick the ways in which artists and HCI designers are negotiating issues of temporality by creating a dynamic and shifting moment of heightened attention in the present that allows for the reinterpretation of past experience and the projection of identity into the future. The final section discusses the findings from these analyses. These point toward the need for a new framework of Performative Experience Design, drawing on both performance and HCI, for understanding the construction, reconstruction and interpretation of identity in performance using digital media.

\section{Theoretical frameworks}

The here and now has long been a subject of fascination. For Dierdre Heddon, autobiographical performance 'can capitalise on theatre's unique temporality, its here and nowness, and on its ability to respond to and engage with the present, while always keeping an eye on the future' (2008: 2). While much of Heddon's attention to time in 
autobiographical performance is focused on the performance of stories about historical events, she also examines the role of autobiographical performance in the construction and the unsettling of identity positions using the concept of memory as a productive force or action rather than a transparent means of access. This action of remembering 'involves considering past events from the location of the present, such that the present provides a perspective from which to give past events particular meanings' (2008: 47). It also involves a 'trick' whereby the act of creating an autobiographical performance begins at the 'end' of the story, the point of writing or devising, and moves backward through memory to the story's beginning (2008: 47). Finally, autobiographical performance implicates the future identity of the performer, whose life story now includes the act of performance. For Heddon, 'though the head turns to look back at the past, the feet stay resolutely pointing forwards, waiting for the heart to lead us towards other possible futures' (2008: 87).

Judith Butler (1999) provides a framework used by Heddon and many others for understanding the construction of identity in autobiographical performance. Her conception of the performative refutes any claims to an essential self that could be revealed through performance. Instead, the individual continually enacts a (gendered) self that is constituted only in the moment of performance. Butler's observations about gender can be applied to the performance of autobiographical material: 'a doing, though not a doing by a subject who might be said to preexist the deed' (1999: 33). Telling autobiographical stories is therefore not a display of pre-existing identity, but rather its moment-by-moment creation.

Similarly, experiences are not stored inviolate in memory, waiting patiently for a singular 'truth' to be revealed and transmitted intact to the audience. Rather, a performer can turn her attention to the present moment of performance and use it to evoke, reflect upon and negotiate past experiences that will be received differently by each audience member. Mike Pearson and Michael Shanks (2001) provide a way of understanding the use of memories and objects from the past in the context of performance. They propose an 'interpretive archaeology' that acknowledges the performative nature of any engagement with memories or objects from the past. It requires a dwelling in the present moment, as the past cannot be fixed and set aside for later use. Photographs or other media that capture an image from an individual's past experience trigger a new occasion for the reinterpretation of those images and the layers of associated memories every time the individual engages with them. 
Seen in this light, an experience that is recounted in an autobiographical performance might be said to have a lifecycle consisting of the perception of its original occurrence, subsequent memories of that experience, any re-engagements with the physical or digital remains of that experience, and any engagements with the memories of others surrounding that experience, all of which is remembered and reinterpreted through the process of devising and the event of performance. This concept of a continuous and interleaved lifecycle reflects the many temporal elements out of which an individual constructs and projects an identity at any given moment. However, it fails to fully articulate the promises of performativity in Butler's sense of the term, where identity is constituted through the present moment of its performance. To gain a richer understanding of performativity as a function of temporality in digitally augmented autobiographical performance, it is helpful to conceive of performance as an event.

Erika Fischer-Lichte (2008) theorizes performance as event, a durational energy exchange requiring live, co-present performer and audience. Performance for her is not a static artefact that can be revisited over time, but neither is it to be understood as the temporally limited perception of an 'autonomous work of art' created by an 'autonomous subject' (2008: 163), as this would result simply in attention to the duration of the spectator's engagement. Rather, for Fischer-Lichte, performance exists as an energetic, ephemeral and emergent event created among performers and spectators, without recourse to fixed intent or meaning. Her aesthetics of performance depends on temporality not just for the space of engagement with a specific person, object or story, but for the emergence of 'an extraordinary state of permanently heightened attention' (2008: 168) to a set of conditions that can never be captured or reproduced. It is the experience of the audience dwelling in this state with a co-present live performer that transforms the everyday into the aesthetic of performance. In the case of digitally augmented autobiographical performance, digital representations of the performer's past intersect with the audience's memories and imaginations and confronted with the physical presence of the performer and other audience members, experiencing what Peggy Phelan (1993) understands as an ephemeral moment full of potential for change. Dwelling in this state of heightened attention, drawn at once to recorded and imagined moments in the past, extends and enriches the experience of the present moment.

This exchange of energy and heightening of awareness seem to be particularly relevant to the duration of an experience and the emergence of identity between performer and audience. In 
identifying the ways in which the spatiality of a performance is generated, Fischer-Lichte describes a performative 'space between' (2008: 114) the real and the imagined or remembered. This 'space between' allows performer and audience to dwell together in memory and imagination. Here, performers can find their interpretations of their own memories influenced by their intersubjective encounter with the audience. The 'space between' can also shape future recollections and interpretations of memories, which gain a new and not entirely transparent layer of perception and affect with each performance. For Fischer-Lichte, the performer is, like her spectators, 'a subject engaged in a continuous process of determining and being determined' (2008: 164), and the 'space between' provides one means of engaging in that process.

Although it is the spatiality of a performance that Fischer-Lichte argues is generated in part through the 'space between', spatiality is only one element of the phenomenon of performance that she defines to be 'experienced as the completion, presentation, and passage of the present' (2008: 94). The introduction of personal digital media such as photographs, which capture or represent an actual moment of time, opens up the performer-audience relationship to include a direct perception of the traces of the past alongside the physically co-present performer. This might be referred to as the 'time between', because it allows performers and audiences to engage with memories, associations and imaginings triggered by both the performer his digital windows on the past. Using the tools of HCI, it is both possible and important to investigate the potential for intersubjective interaction in the 'time between' brought about by these discordant temporalities.

Fischer-Lichte's emphasis on the emergent and interactive processes of performance seems to extend Heddon's understanding of the role of autobiographical performance in the construction of identity, as well as Pearson and Shanks' concept of interpretive archaeology. However, her notion of performance as event would seem to exclude a digital element, as she explicitly rejects any sense of presence for digital media objects in and of themselves (2008: $100)$. We challenge this view in the context of autobiographical performance. Such an outright rejection of presence, though fully in keeping with her overall argument, is vulnerable to refutation following the arguments of Philip Auslander, who rejects ontologically based claims for live performance (1999). Rather, we suggest that the presence effects of digital media can provide another means of engaging with the past experience of Fischer-Lichte's 'radically' present performer (2008: 99) through the overlap of '[p]erception, 
association, memory, and imagination' (2008: 112). Digital media which function not to stand in for but to augment the presence of the live human subject should therefore be able to contribute to the conditions in which performance is constituted. This is suggested by a model of domestic photography proposed by one of us (Frohlich) to understand the personal and social interactions around personal photographs and additional media such as sound. In the absence of other models for understanding the dynamics of photograph use, Frohlich (2004) developed a 'diamond framework' showing relationships between photographer, subject, audience and photograph. This terminology was inspired by Barthes' (1981) discussion of the interpretation of photographs, and work by Schaverian (1991) on the powerful interactions that can take place between client and therapist in art therapy consultations. Both authors suggest an active role for images (and other media) themselves in influencing the perceptions and emotions of viewers, and this is built into the diamond framework, which shows the photograph itself as a key agent in photographic encounters (see Figure 3).

\section{INSERT FIGURE 3 ABOUT HERE}

Dotted line connections between a photograph and the human agents shown in Figure 3 involve solitary reflections of various kinds. These are some of the mechanisms by which images can influence observers directly. Private review of a photograph by the photographer involves a kind of recognition of the scene and its moment of capture. This perception is somewhat different for the subject of the photograph who never viewed the scene from this perspective. However, they may recall the event in which they were photographed and are

given additional insight into their own appearance and part in it, as in a mirror. Perception of the photograph is different again for an audience member who was not present at the time the image was taken. They must interpret the image in and of itself, as in a gallery situation.

Solid line connections between agents in the model point to three kinds of social interactions that can take place around images. These should be viewed in the context of triangular interactions connecting the human participants with the photograph in each case. When photographer and subject interact around an image they can reminisce about the event of which both were a part. However, when either of them shares the image with a third party audience member who was not present at the original event, storytelling is involved to convey the story of the photo and aid its interpretation by the audience. 
Frohlich (2004) goes on to show the effect of introducing sound recordings of various kinds on each interaction in the framework, and provides evidence for different characteristics of reminiscing and storytelling talk in photo sharing conversations ('phototalk'). Reminiscing talk contains more turns, more overlaps and a greater mixture of initiative between participants than storytelling talk, which is controlled largely by the storyteller within a prescribed 'space' bracketed by a story preface and closing. Both involve audience participation and interaction around the images, and serve to keep the conversation interesting and understandable to all parties. Like Heddon, Frohlich suggests that memory for an event might be influenced by its different tellings over time, and he introduces the idea of 'photo-outings' with different combinations of audience members involved each time.

These various theories of autobiographical performance reflect the perspectives of the theorists as much as the properties of performance itself. In particular, the performance theorists above stress the nature of performance as an event and the interplay between perceptions of memory and identity between performers and audience. Media theorists and HCI practitioners stress the role of media and the active part media themselves can play in social interactions. As both performance studies and HCI point to the importance of time in autobiographical performance, we can position them as complementary approaches. Digitally augmented autobiographical performance lies at their intersection and is constituted through a nuanced imbrication of past, present and future that requires a 'time between' for a co-present performer and audience to explore.

Further work to understand and advance this type of engagement is long overdue. It represents a step forward in the practices of autobiographical performance and digital performance. It also represents an innovation in the understanding of the 'user' in HCI and interaction design as not just a goal-driven agent, or even an emotional agent pursing diverse and contingent goals. Instead, 'users' take on a role, either performer or audience member (though individuals may swap roles), to engage in a performative, aesthetic event. They do so not primarily with a particular computing device but with the media represented through this device. In other words, while the interaction certainly relies upon the affordances of a particular device, the user primarily engages with the media content itself. This engagement prompts the audience and the performer to look at once into the past and the present to create an identity that is forever in the process of transformation. 
We argue for the development of a strand of design-led research, Performative Experience Design, which will draw on performance and interaction design to advance the understanding of digital media practices in the context of live, co-located performance. The following case studies from the fields of performance and HCI illustrate the workings of time in digitally augmented autobiographical performance and provide examples of the key elements of Performative Experience Design.

\section{Autobiographical performance case studies}

Cape Wrath (2012) is a work in progress about 'a family as something that exists in time' (personal communication) by Alexander Kelly, a member of the UK performance group Third Angel. It arose from Kelly's desire to retrace a journey to Cape Wrath, the northernmost point in Scotland, undertaken by his grandfather about two decades previously. Originally unsure whether Cape Wrath would become a primarily live or mediatized work, Kelly began recording his journey on video, but quickly saw that this medium would fail to convey the uniqueness of either his grandfather's original experience or his own experience, unfolding at that moment (personal communication). He decided instead to use everyday social media practices as part of his performance practice: he documented his travels via the social networking applications Twitter and Instagram and created an online story from these traces using Storify. Kelly then used that digitally mediated story as a key resource for his live performance. He felt it was only through his physical presence on stage, augmented with still photographs and only one video, that he would be able to turn his very personal and understated story into a compelling experience for the audience (personal communication).

As a work in progress, Cape Wrath was performed as part of the Forest Fringe festival at The Gate Theatre in London on 9 April 2012. Kelly announced his plan for the evening: to tell us the story his grandfather had told Kelly when he (Kelly) was 19 years old. He did more than speak his grandfather's words, though: he explained to the audience which family members were present at that original telling and where they all sat around the table, but he did not embody or inhabit any of these characters. In this way he invited the audience into a particular 'space between' the real and imagined, past and present: his own past experience, his memory of the past experiences of his family members, his present-moment feeling about this event, what it said about him to claim this private part of his history in public, and what it said about the audience to imaginatively recreate this scene. 
At Kelly's table was a laptop controlling the projection of approximately sixteen photographs of his journey to Cape Wrath (including one photograph of a topographical map of Cape Wrath), none of which featured Kelly himself. The personal nature of these photos offered a contradiction: they documented the external details of his trip, which underscored the lived experience of Kelly's journey. At the same time, the absence of Kelly himself in the photographs offered another means for the audience to imagine themselves into Kelly's place. These absences and slippages allowed another 'time between' for the audience to make sense of and engage with Kelly as a performer and as a fellow human being, performing the stories that made him who he was for the duration of that staged encounter.

At the end of the performance, Kelly dealt explicitly with the ways in which shared experiences lay down future memories out of which individual identities will be built. He began to read from notes attached to a clipboard: 'About a year ago, although I write this about a year ago, so about two years ago now...' He then read a piece about his young daughter: anything she experiences right now, including any experience he shares with her, might end up having become her earliest memory. Shifting focus back to his grandfather, Kelly read out the facts of that earlier trip as his grandfather had recorded in his diary. Kelly stood up and pointed out the suit he was wearing: it was his grandfather's. The final line of the performance was this: 'It's 15 March 2012, 11:52 a.m., as I write this. I want to go back, but I don't know in the rules of this project if I'm allowed. Thank you for listening.' Indeed, it seems that the 'rules' of Cape Wrath were to bring together strands of past, present and future in order to bring alive the heightened and extended present-moment experience of the audience, imagining their way through Kelly's stories. These rapid shifts between times and perspectives map out a complex web of temporal disjunctions, interpretations and affect out of which both performer and audience member could construct their own sense of Kelly, his grandfather, his young daughter, and their own experience of genealogical time.

The first element of the autobiographical trilogy of which Cape Wrath is the third was Class of '76 (2000), a work that relied less on digital media but which provides another strong example of the 'time between' hinted at by the Kelly's wearing his grandfather's suit in Cape Wrath. For Class of '76, Kelly used a projection of his infant school class photograph from 1976 as the trigger for a performance staged in the very room in which the photograph had been taken. This performance depended on two key elements: the projected photograph and the physical presence of the performer, who had been one of the children in the photograph. 
Kelly projected the photograph at approximately life size against the wall behind him but simultaneously lit that wall so that the projection could not be seen. One by one, he held up blank pieces of card, allowing each one to catch a single projected face (Figure 4).

\section{INSERT FIGURE 4 ABOUT HERE.}

The photograph was the only visual trace to the people named in the show. Yet this archival 'proof' of Kelly's connection to the people, memories and stories in his performance was the ephemeral projection of a single photograph, shown only in fragmented glimpses (Heddon 2008: 166). Audiences were confronted with the discontinuity between young boy and grown man. At the same time, Kelly used his performance to assert a continuous identity with his childhood self, using the photograph to claim authority to speak about the experiences of this group of individuals. The contradiction between these two positions opened a 'time between' the real and the imagined for both performer and audience to question the rights of the present-day Kelly to ascribe his adult-inflected interpretations of the past to the small boy looking out from the photograph. Indeed, it was in the creation of this space for his copresent audience to dwell with him, his stories and his photograph that Kelly was able to highlight the innumerable temporal gaps between experience, memory, and imagination. It was the 'heightened state of attention' in this performative moment in time created by the projected media, the physically present performer, and that specific, situated audience that invited engagement with these many layers of past experience.

\section{Autobiographical media sharing case studies}

The audiophoto desk is typical of work in Human Computer Interaction (HCI) in that it is inspired by prior design artefacts and informed by literature on everyday practice of particular kinds: in this case the project emerged from Frohlich's (2004) exploration of the role of sound in domestic photography. The aim of the design work is to address issues in practice and bring new technology to bear in ways that improve and enhance the way things are usually done, in this case through the use of sound capture on digital cameras and cameraphones. Frohlich's earlier studies showed that families enjoyed creating audio-photo combinations of various kinds, and the audiophoto desk was conceived as a new way of sharing these through physical prints. In contrast to an earlier solution which encoded a sound file on a chip within the paper and played it back from a handheld player (Frohlich et al. 
2000), the desk simply used image recognition of the prints from an overhead camera to fetch and play an associated sound file with the same filename (Frohlich et al. 2004). This was controlled by a PC under the desk loaded with a CD-ROM containing audiophoto content for different photo sets (Figure 5). An additional feature of the desk is that it allowed several audiophotos to play at once and tracked their position on the desk surface. Prints could be pushed to the back of the desk to reduce the volume of their associated sound or right/left to adjust their stereo balance. The overall effect was to support a kind of 'DJing with photos' in which a audiophoto collage could be assembled and controlled manually by sliding different photos around the desk surface (Lindley and Monk 2004).

\section{INSERT FIGURE 5 ABOUT HERE}

Depending on the design of the original audiophoto materials, a great number of different kinds of evocative sound and image-scapes could be 'played' on the desk. An initial personal discovery was that content had to be specifically designed for the desk itself and worked best with a small combination of ambient sound, voiceover and musical photos relating to the same event or story. Playback was unique in each instance, as the effects depended on exactly where and when photographs were placed on the desk throughout the session. The sound clips did not loop but rather played out and stopped, so that each session became a performance of overlapping clips of different durations. While 'storytelling' could be done purely through the media themselves, it was more common for users of the desk to want to tell their stories live with the media in a supporting role.

Two small evaluations of use were carried out in different laboratory and exhibition contexts with groups of students or visitors to the exhibition (Blythe et al. 2008, Lindley and Monk 2004). The students found that authoring the materials provided opportunities for humour in combining mis-matching photos and sound clips, and that the sounds provided additional talking points in conversation as well as the images (Blythe et al. 2008, Lindley and Monk 2004). However, the sounds were found to get in the way of ordinary conversation at times, especially when they contained voiceover themselves. Music and ambient sounds added to the emotion of the session and could be talked over, when played at a suitable volume.

Visitor reactions to the exhibition were very positive, referring to the 'magic' of the technology as a motivating factor in listening to stories of the area (Blythe et al. 2008). The desk was also effective in eliciting reciprocal stories and recollections by visitors relating to 
those contained within the audiophoto materials on display.

A similar motive to investigate and extend autobiographical storytelling with digital media prompted the development of 4Photos, the digital photo display prototype described at the beginning of this article (ten Bhömer et al. 2010, O'Hara et al. 2012). The device streams four photographs simultaneously from the Facebook pages of dinner party guests onto a rhomboid display placed in the middle of the table (Figure 2) in a kind of ticker-tape photostrip. In field studies, work colleagues, friendship groups and extended family groups interacted with the 4Photos display while sharing a meal together. The photographs topicalized autobiographical talk, and created an opportunity for participants to ask more intimate questions than usual about each others' lives and identities. The flow of the photos prompted a dynamic switching of roles in the diamond framework (Figure 3), where changes of media shift the relationships of participants around the photograph. The way in which this happened over time is particularly complex and interesting for the current paper. Whereas users of the audiophoto desk had the opportunity to craft and adjust story performances over time, 4Photos participants needed be quick in spotting a detail of interest, selecting it for shared view and introducing it into the conversation itself. The resultant talk was highly interactive, and dependent upon the seating position of participants, the ongoing flow of conversation and the actions of others. Hence much of the analysis of the trial sessions is about the spatio-temporal arrangements and dynamics of device use, and the moment-by-moment access to the media presented by it.

The 4Photos and audiophoto desk explorations begin to show how participant engagement might be further extended through direct access to autobiographical media. In the extreme case, they might be played without further storytelling, but are more commonly used as triggers for interrogation of the author or interpretation of their ongoing narration (Frohlich 2004: 133). While artists from a performance background may want the media to assume second place to their performance, findings from HCI and interaction design show that media can sometimes take centre stage, getting in the way of human interactions or taking them in directions the participants do not want to go. They call attention to the need for careful design of both media content and media player in performance settings, and a sensitivity to the temporal unfolding of mediated encounters and their experiential effects on audiences of different kinds. Such design can facilitate reminiscing and storytelling encounters that allow people to express themselves as much as they wish to or even to discover unexpected but 
welcome new levels of intimacy or participation.

\section{Discussion}

These case studies reveal some of the many ways in which digitally augmented autobiographical performance can work. They create the conditions for a performative and multilayered engagement with past, present and future concentrated in the live interaction between co-present performer and audience. The performers, whether theatre professionals or dinner party guests, engaged with memory during the performance: memories of the events they spoke about, memories of other performances or tellings, and associated but unspoken memories. These memories rubbed up against the digital traces of those events, providing a 'proof' at once ephemeral and incontrovertible. The performers also had an eye on the future, knowing that they and their audiences would now include this performance event and its content in their understanding of the performer's own identity in the days and years to come. Most importantly, the performances hinged upon the lived moment of their experience. Memories are re-interpreted and re-imagined from the ever-changing perspective of the current moment. Roles may shift in a heartbeat. It is in allowing a 'time between' for performers and audiences to carry out the productive work of memory (Heddon 2008), of 'interpretive archaeology' (Pearson and Shanks 2001), and of the dynamic creation of identity (Butler 1999), that digitally augmented autobiographical performance can heighten attention (Fischer-Lichte 2008) to a rich, intersubjective, performative encounter.

\section{INSERT FIGURE 6 ABOUT HERE}

Some of this complexity can be illustrated as an adaptation of the 'diamond framework' (Figure 3). The photograph or 'image' at the top of the diagram can be generalized to any kind of media item. Furthermore, in the context of autobiographical performance, the separate nodes of 'photographer' and 'subject' may be collapsed, as the performer takes on the role of both subject and owner/creator of the media object. Thus, the diamond becomes a triangle made up of performer, audience, and media (Figure 6). The action taking place between performer and media is recognition - in other words, an act of memory, although he actively reinterprets that memory from the vantage of the moment of its recall. The action taking place between audience and media is interpretation - in other words, an act of imaginative association and efforts to imagine oneself into the performer's experience. The 
combination of media reflecting personal experience with the physically present performer opens up the 'time between' past and present for the audience to dwell in during the performance. Based on the diamond framework, the action taking place within that 'time between' is storytelling.

A subtlety not captured in the new diagram is that memory and imagination are not mutually exclusive. For example, any gaps or errors introduced in the act of recall, which is itself an interpretive act, could lead to new acts of imagination in the performer. Conversely, the audience's acts of imagination can involve associations and memories of their own life experiences. If they go on to share these experiences, they become performers in their own right.

Our analysis indicates the first steps of an answer to the initial question we posed: 'What is the role of personal and autobiographical media in the here and now of live performance?' Personal and autobiographical media within the context of autobiographical performance have the power to engage audiences in an extended moment of memory and imagination. In more conversational situations, they can prompt participants to switch in an instant between the performer's act of memory (recognition and recall) and the audience's imaginative act of interpretation. They can prompt a quick turn to reminiscence, or take the floor for storytelling. They can create more intimate bonds. In a theatrical setting, where vocal audience participation is not solicited, they can promote as well as restrict the audience's imagination as they navigate their interpretation of the performer's words alongside the potentially rich associations of his photographs. They have the potential to alter the meanings generated by the audience as 'perception, association, memory, and imagination overlap[]' (Fischer-Lichte 2008: 112). While individuals are certainly capable of generating intimate, compelling autobiographical performances or conversations in the absence of media (digital or otherwise), digital media are potentially powerful agents for extending and enriching the temporal experience of storytelling in that performance or conversation.

Now we must ask how we can design for performative experiences using personal and autobiographical media. The crux of the answer seems to be the potential of the present moment to create space for a dynamic and temporally rich storytelling experience that goes beyond the recitation of narrative to passive spectators. Designs must encourage emergent behaviours, associations, feelings, relationships, and insights among the participants engaged 
in heightened attention and energetic exchange. The present moment must be allowed to extend beyond its regular boundaries to give participants the space and time to find their way among the contradictions, dissonances, gaps, twists and unexpected realizations that can occur.

Performative Experience Design must respect the fact that each digital artifact represents an element of the performer's lived experience and personal identity, and that by inviting an audience to listen or contribute, the performer has added this part of his life in some small way to the lived experience and personal identity of each member of his audience. It must recognize the agency inherent in digital media while reserving due attention to the physical presence of the performer, who is also a subject of his performance. Performative Experience Design seeks to create such interactions, allowing the space and time for people to create rich engagement, enquiry and surprise out of the performance encounter.

\section{References}

Auslander, P. (1999), Liveness: Performance in a Mediatized Culture, London and New York: Routledge.

Barthes, R. (1981), Camera Lucida, New York: Hill and Wang.

Blythe, M., Robinson, J. \& Frohlich, D.M. (2008), 'Interaction Design and the Critics: What to Make of the "Weegie"', ACM Press: New York, pp. 53-62.

Butler, J. (1999), Gender Trouble: Feminism and the Subversion of Identity, New York and London: Routledge.

Fischer-Lichte, E. (2008), The Transformative Power of Performance: A New Aesthetics, London: Routledge.

Frohlich, D., Adams, G. \& Tallyn, E. (2000), 'Augmenting Photographs with Audio', Personal and Ubiquitous Computing, 4, pp. 205-208.

Frohlich, D.M. (2004), Audiophotography: Bringing Photos to Life with Sounds, Dordrecht, Boston and London: Kluwer Academic Publishers.

Frohlich, D.M., Clancy, T., Robinson, J. \& Costanza, E. (2004), The Audiophoto Desk. Proceedings of 2AD, Second International Conference on Appliance Design. Bristol, UK.

Goffman, E. (1959), The Presentation of Self in Everyday Life, Garden City, NY: Doubleday. Heddon, D. (2008), Autobiography and Performance, Basingstoke: Palgrave Macmillan.

Lindley, S. \& Monk, A. (2004), 'DJing with Photos', The 18th British HCI Group Annual Conference, pp.

O'Hara, K., Helmes, J., Sellen, A., Harper, R., ten Bhömer, M. \& van den Hoven, E. (2012), 'Food for Talk: Phototalk in the Context of Sharing a Meal', Human-Computer Interaction, 27, pp. 124-150.

Pearson, M. \& Shanks, M. (2001), Theatre/Archaeology: Disciplinary Dialogues, London and New York: Routledge.

Phelan, P. (1993), 'The Ontology of Performance: Representation without Reproduction'. Unmarked: The Politics of Performance. London: Routledge.

Schaverien, J. (1991), The Revealing Image: Analytical Art Psychotherapy in Theory and 
Practice, London and Philadelphia: Jessica Kingsley Publishers.

ten Bhömer, M., Helmes, J., O'Hara, K. \& Hoven, E.v.d. (2010), '4Photos: A Collaborative

Photo Sharing Experience', Proceedings of the 6th Nordic Conference on Human-

Computer Interaction: Extending Boundaries, ACM Press: New York, pp. 52-61. 